FACULdADE DE CIÊNCIAS ECONÔ MICAS DA UFRGS

MACROECONOMIA DO BRASIL PÓS-1994 LUIZ CARLOS BRESSER-PEREIRA

DESENVOLVIMENTO ECONOMMICO, PREFERÊNCIA PELA LIQUIDEZ E ACESSO BANCÁRIO: UM ESTUDO DE CASO DAS MESORREGIÓES DE MINAS GERAIS

MARCO CROCCO, CLAUDIO BARRA DE CASTRO, ANDERSON CAVALCANTE E VANESSA DA COSTA VAL

FRIEDMAN E O MONETARISMO: A VELHA TEORIA QUANTITATIVA DA MOEDA E A MODERNA ESCOLA MONETARISTA

GENTIL CORAZZAE RODRIGO L. KREMER

BOLLHAS RACIONAIS, CICLO DE PREÇOS DE ATIVOS E RACIONALIDADE LIMITADA: UMA AVALIACAOO CRITICA DOS MODELOS NEOCLÁSSICOS DE BOLHAS ESPECULATIVAS JOSÉ LUIS OREIRO

VULNERABILITY INDICATORS OF THE TWIN CRISES: THE EAST ASIAN EPISODE

TITO BELCHIOR SILVA MOREIRA

IMPACTOS POTENCIAIS DA NEGOCIAÇÃO DA ALCA SOBRE OS INVESTIMENTOS EXTERNOS EM SERVIÇOS PROFISSIONAIS NO BRASIL

MICHEL ALEXANDRE, OTAVIANO CANUTO E GILBERTO TADEU LIMA

TEORIA MARXISTA DO VALOR: UMA INTRODUÇẢO ALFREDO SAAD FILHO

UM ESTUDO EMPIRICO DOS CICLOS POLITICO. ECONOOMICOS NO BRASIL

ATHOS PRATES DA SILVEIRA PREUSSLER E MARCELO SAVINO PORTUGAL

RELENDO CHANDLER, WILLIAMSON E NORTH PARA ENTENDER O PROCESSO DE FORMACĀO DAS ESTRADAS DE FERRO NO BRASIL

JEFFERSON ANDRONIO RAMUNDO STADUTO

WEIMAR FREIRE DA ROCHA IR. E CLAIITON ATAIDES DE FREITAS

MATRIZ DE INSUMO-PRODUTO PARA A ECONOMIA TURISTICA BRASILEIRA: CONSTRUCCÃO E ANÁLISE DAS RELAÇÓES INTERSETORIAIS

FRANCISCO CASIMIRO FILHO E JOAQUIM JOSÉ MARTINS GUILHOTO

SEÇĀO ESPECIAL: AVALIAÇŌES INICIAIS DA POLITTICA ECONÓMICA DO GOVERNO LULA

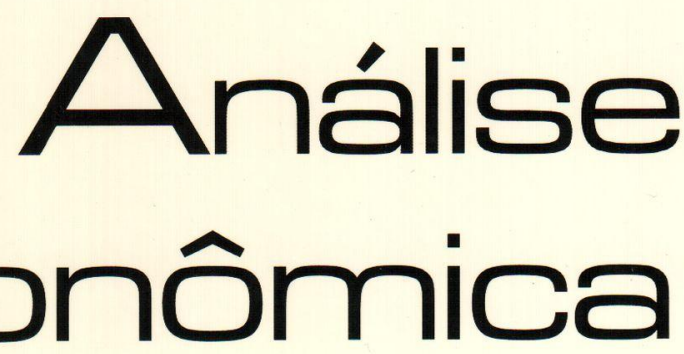


Universidade Federal do Rio Grande do Sul

Reitora: Profa. Wrana Maria Panizzi

Faculdade de Ciencias EConómicas

Diretora: Prof Pedro César Dutra Fonseca

Centro de Estudos e Pesquisas Economicas

Diretor: Prof. Gentil Corazza

Departamento de Ciéncias económicas

Chiefe: Prof. Ricardo Dathein

Curso de Pós. Graduação em Economia

Coordenador: Prof. Eduardo Pontual Ribeiro

Programa de Pós-Graduação em Desenvolvimento Rural

Coordenador: Prof. jalcione Almeida

CONSElHo EDITORIAL:

Carlos G. A. Mielitz Netto (UFRGS), Eduardo A. Maldonado Filho (UFRGS), Eduardo P. Ribeiro (UFRGS), Eleutério F. S. Prado (USP), Eugênio Lagemann (UFRGS), Fernando Cardim de Carvalho (UFRJ), Fernando Ferrari Filho (UFRGS), Fernando de Holanda Barbosa (FGV/RJ), Flávio Vasconcellos Comim (UFRGS), Gentil Corazza (UFRGS), Giácomo Balbinotto Netto (UFRGS), Gustavo Franco (PUC/RJ), Jan A. Kregel (UNCTAD), João Rogério Sanson (UFSC), Joaquim Pinto de Andrade (UnB), Jorge Paulo Araújo (UFRGS), Marcelo S. Portugal (UFRGS), Maria Alice Lahorgue (UFRGS), Paul Davidson (University of Tennessee), Paulo D. Waquil (UFRGS), Pedro C. D. Fonseca (UFRGS), Philip Arestis (Levy Economics Institut of Bard College), Roberto C. de Moraes (UFRGS), Ronald Otto Hillbrecht (UFRGS), Sabino da Silva Porto Jr. (UFRGS), Stefano Florissi (UFRGS) e Werner Baer (University of Illinois at UrbanaChampaign).

COMISSÃO EDITORIAL:

Eduardo Augusto Maldonado Filho, Fernando Ferrari Filho, Gentil Corazza, Marcelo Savino Portugal, Paulo Dabdab Waquil e Roberto Camps Moraes.

EDIroR: Prof. Fernando Ferrari Filho

Editor Adunnio: Prof. Gentil Corazza

SECRETÁrla: Clarissa Roncato Baldim

REVISÁO DE TEXTOS: Vanete Ricacheski

EDITORaÇão Eletrónica: Vanessa Hoffmann de Quadros

Fundador: Prof Antônio Carlos Santos Rosa

Os materiais publicados na revista Análise Econômica são da exclusiva responsabilidade dos autores. É permitida a reprodução total ou parcial dos trabalhos, desde que seja citada a fonte. Aceita-se permuta com revistas congêneres. Aceitam-se, também, livros para divulgação, elaboraçāo de resenhas e recensōes Toda correspondência, material para publicaçāo (vide normas na terceira capa), assinaturas e permutas devem ser dirigidos ao seguinte destinatário:

Análise Econômico

PROF FERNANDO FERRARI FILHO Revisła Análise Econômica - Av. João Pessoa, 52 CEP 90040-000 PORTO ALEGRE - RS, BRASL Telefones: (051) 316-3513 - Fax: (051) 316-3990 E-mail: rae@ufrgs.br

Ano 21, $n^{\circ} 39$, março, 2003 - Porto Alegre

Faculdade de Ciências Econômicas, UFRGS, 2003

Periodicidade semestral, março e setembro.

Tiragem: 500 exemplares

1. Teoria Econômica - Desenvolvimento Regional.

Economia Agrícola - Pesquisa Teórica e Aplicada -

Periódicos. I. Brasil

Faculdade de Ciências Econômicas,

Universidade Federal do Rio Grande do Sul 


\section{Os Seis Primeiros Meses da Política Econômica no Governo Lula: Exorcizando o Fantasma da Ruptura ${ }^{1}$}

Marcelo S. Portugal ${ }^{2}$

Paulo Chananeco F. de Barcellos Neto

\section{Introdução}

A política macroeconômica do Governo Lula, nos primeiros meses de governo, seguiu a mesma orientação que norteou o segundo mandato do ex-presidente Fernando Henrique Cardoso. Manteve-se o tripé de sustentação da economia baseado no sistema de metas de inflação, como uma forma de "despolitizar" a política monetária, em metas rígidas para no superávit primário, com o intuito de garantir a solvência de médio e longo prazos do setor público, e o regime de câmbio flutuante, que deixa para os agentes de mercado o papel principal na determinação da taxa de câmbio.

Agindo assim, o novo governo parece frustrar expectativas de que a chegada do Partido dos Trabalhadores ao poder seria seguida de uma ruptura na condução da política econômica, algo ainda defendido por algumas pessoas ligadas ao núcleo intelectual tradicional do partido. Diante da opção pela responsabilidade, ao invés do voluntarismo, podemos afirmar que está em curso no Brasil um processo de exorcizar o fantasma da pirotecnia econômica. No decorrer do primeiro semestre de 2003, os indicadores de confiança melhoraram sensivelmente, refletindo a opção pela continuidade da agenda macroeconômica.

Esta escolha torna-se ainda mais importante quando acrescentamos os ganhos de credibilidade de longo prazo advindos da redução dos efeitos dos processos eleitorais no Brasil sobre a realização de experimentos alternativos na condução da política econômica. Assim, será objetivo do presente artigo analisar as escolhas econômicas nos primeiros seis meses do governo Lula, seus principais pi-

\footnotetext{
${ }^{1}$ Agradecemos os comentários de Júlia C. Klein, Amanda Pimenta e Gustavo Russomano a uma versão anterior deste artigo.

${ }^{2}$ Professor Titular em economia na UFRGS e pesquisador do CNPq.

${ }^{3}$ Doutorando em economia (UFRGS).
} 
lares e resultados de curto prazo. Por fim, apresentamos comentários sobre a possibilidade de uma ruptura deste comportamento, em face de algumas alternativas expostas até o presente momento.

\section{O tripé da política econômica}

O principal pilar de sustentação da política econômica, ratificada pelo atual governo, é o sistema de metas de inflação implementado no País desde 1999. Embora o conceito do regime tenha permanecido o mesmo, houve modificações marginais ao longo dos primeiros seis meses. A carta aberta, enviada pelo Presidente do Banco Central ao Ministro da Fazenda em 21/01/2003, além de apresentar as justificativas para o não cumprimento da meta de 2002, oficializou a utilização de uma meta ajustada de inflação para os anos de 2003 e 2004, definida em $8,5 \%$ e 5,5\%, respectivamente. A justificativa desta implantação foi o reconhecimento do Banco Central de que para cumprir a meta original (de $4 \%$ em 2003 e 3,75\% em 2004) existiriam "custos desnecessários" para a economia, leia-se retração demasiada na atividade econômica ${ }^{4}$.

Esta nova metodologia apresentava como vantagem a possibilidade de ajustar a meta de inflação ao longo do mesmo ano, em função de determinados choques inflacionários. Como desvantagem, por outro lado, estava a sua complexidade e falta de sinalização fixa, de tal forma que se podia incorrer num perigoso sentimento de que a meta de inflação estaria convergindo para os índices, ao invés de os índices convergirem para as metas. Na reunião do Conselho Monetário Nacional de junho, contudo, foi retomado o sistema clássico de metas de inflação, mantendo-se a meta de $5,5 \%$ para 2004 e $4,5 \%$ para 2005. Desta forma, assim como ocorreu após o choque cambial de 1999, a opção do governo foi no sentido de um combate gradualista à inflação.

A demonstração de comprometimento da equipe econômica do Governo Lula com o sistema de metas de inflação foi dada nas novas elevações na taxa básica de juros no início de 2003, em face do comportamento dos índices de preços que carregavam forte componente inercial do choque cambial ocorrido no ano anterior.

\footnotetext{
4 Para uma avaliação econométrica e uma discussão teórica e aplicada mais detalhada do regime de metas de inflação no Brasil, ver Silva e Portugal (2002) e Portugal, Madalozzo e Hillbrecht (1999).
} 
Do ponto de vista da política fiscal, novamente temos uma continuidade da política anterior, baseada na geração de um superávit primário compatível com uma trajetória de estabilidade da relação dívida/PIB e, conseqüentemente, solvência da dívida pública no médio e longo prazos. A meta de superávit primário foi estabelecida em $4,25 \%$ do PIB para 2003, acima da meta anterior $(3,75 \%)$ e tam. bém maior que o superávit primário de 3,91\% atingido em 2002.

Ao impor uma meta rígida de desempenho fiscal, o governo mostra comprometimento com a solvência do endividamento público, bem como vai ao encontro de políticas que são seguidas em muitos países com economias estáveis. Novamente, o estabelecimento deste parâmetro não está isento de críticas de parte da sociedade que acredita que mostrar responsabilidade com os recursos públicos implica em "custos sociais" demasiados. Contudo, destaca-se que a determinação de metas fiscais faz parte da Lei de Responsabilida. de Fiscal, e a trajetória crescente da dívida pública interna nos últimos anos levou este governo a fixar um superávit desta magnitude.

Ainda no campo fiscal, o novo governo apresentou à sociedade duas propostas de reformas constitucionais complexas e polêmicas, as reformas tributária e previdenciária, que já haviam sido discutidas no governo anterior e que podem melhorar sensivelmente a capacidade do Estado de cumprir com seus compromissos, embora os resultados ainda sejam incertos. $\mathrm{Na}$ reforma previdenciária, destacam-se pontos polêmicos que afetam negativamente grande parte do tradicional eleitor do PT (funcionários públicos), em prol de uma desejável solvência financeira do sistema previdenciário, apesar dos grandes custos políticos que estas medidas deverão ter no futuro. Em relação à reforma tributária, os maiores benefícios deverão advir da unificação da legislação ICMS, frustando expectativas de maiores alterações no sistema tributário vigente.

O último pilar do tripé da política econômica é o sistema cambial, que continuou a ser baseado no câmbio flutuante. Nesse particular, ganhou espaço na mídia a discussão sobre a imposição de algum tipo de controle sobre o comportamento do câmbio, diante da valorização do real no início do governo. Obviamente, em um sistema de taxas de câmbio flutuantes, associado a um regime de metas de inflação, não cabe o estabelecimento de limites mínimos ou máximos para a taxa de câmbiós. É um grande equívoco tentar

\footnotetext{
${ }^{5}$ Ver a este respeito, por exemplo, Bernanke, Laubach, Mishkin, e Posen (1999).
} 
fixar a taxa de câmbio. Quando a taxa é fixada em um valor muito baixo (valorizada), temos, em geral, um grande desequilibrio no balanço de pagamentos em conta corrente, tal como ocorreu entre 1995 e 1998. Por outro lado, quando a taxa é fixada em patamares muito elevados (desvalorizada), tal como ocorreu nos anos 1980, o resultado é uma inevitável aceleração da inflação e um esgotamento da capacidade de crescimento em função dos altos custos de importar 6 .

É importante ter claro, todavia, que a inexistência de metas de câmbio não impede que o Banco Central atue no mercado cambial. Desde a criação do sistema de metas de inflação, o Banco Central já atuou diversas vezes no mercado de câmbio. Na verdade, sempre que uma variação significativa da taxa de câmbio ocorrer, sem ligação direta com os fundamentos econômicos, cabe ao Banco Central atuar no mercado tentando evitar tal fenômeno. Em 2001, por exemplo, foi instituída uma política de venda diária de cerca de US\$ 50 milhōes, com o objetivo de fornecer liquidez ao mercado de câmbio. Criaram-se, posteriormente, os contratos de swap cambial, cujo objetivo foi o de fornecer hedge cambial que, por um problema de falha de mercado, não é oferecido pelo sistema financeiro privado e pelos exportadores brasileiros. Note-se, novamente, que em nenhum momento estas intervenções foram inspiradas em uma avaliação governamental de que era necessário "defender" um certo nível de taxa de câmbio. A literatura de metas de inflação recomenda atuaçōes no mercado de câmbio apenas para amortecer variações transitórias da taxa de câmbio. Movimentos permanentes, ligados aos fundamentos macroeconômicos, não devem ser objeto de intervenção por parte do Banco Central.

Como resultado desta política, autodenominada de Lula light, diversos indicadores econômicos apresentaram melhoras expressivas, como o risco-país, a taxa de câmbio e os índices de preços. Como exemplo, podemos destacar a questão da "vulnerabilidade externa", um dos principais pontos de crítica à política econômica do governo anterior, que vem sendo resolvida, ou no mínimo reduzida substancialmente, com a geração de um grande superávit comercial e com a volta das fontes de financiamento externo para a economia brasileira. Os dados disponiveis apontam para um supe-

\footnotetext{
' Sobre as grandes dificuldades para a estimação correta de uma "taxa de câmbio de equilíbrio", ver Merlin e Portugal (2002).
} 
rávit comercial acumulado nos últimos doze meses, até junho, de US $\$ 20,9$ bilhões. É significativo que este superávit esteja sendo conseguido com o aumento de exportaçōes em uma conjuntura internacional não muito favorável.

\section{Críticas Marginais versus "Plano B"}

O eixo central da política econômica é, portanto, a continuidade. Esta estratégia visa à construção de credibilidade na política econômica de forma a garantir a manutenção da estabilidade macroeconômica nos próximos anos. Para usufruir os benefícios desta escolha, o presidente Lula tomou decisōes importantes, como a retirada de seu partido a condução da política econômica. Todas as secretarias importantes do Ministério da Fazenda foram isoladas dos petistas, tendo sido entregues a técnicos, muitos dos quais haviam trabalhado no governo FHC. Na direção do Banco Central ocorreu o mesmo fenômeno, com a manutenção da diretoria anterior e a escolha de um banqueiro internacional que era deputado eleito pelo PSDB para presidente da instituição. $O$ único petista que atualmente tem influência na política econômica do governo é o ministro Antônio Palocci, que funciona como "algodão entre cristais", viabilizando dentro do PT a política econômica atual.

Embora a opção de manter o sistema de metas de inflação com câmbio flutuante e aperto fiscal tenha sido correta, o novo governo está longe de ser isento a críticas, que podem ser divididas em sutis ou marginais, embora não menos importantes, e estruturais. Em relação às críticas sutis, o timing do processo de redução das taxas de juros pode, por exemplo, ser questionado. Quando examinamos as taxas de juros no mercado futuro, as taxas dos leilōes primários de LTNs e também os índices de inflação, pode-se argüir que já havia espaço para uma redução da taxa SELIC na reunião do Copom no mês de maio?.

Outra crítica possivel salienta que a meta de $8,5 \%$ para a inflação em 2003 foi muito baixa, tendo o governo se precipitado em determinar a nova meta ajustada já em fevereiro, quando ainda não

${ }^{7}$ O governo Lula estaria trocando crescimento econômico por combate à inflação, movendo a economia brasileira ao longo da Curva de Phillips, de maneira exagerada. As estimativas de Curva de Phillips para o Brasil apresentadas em Tejada e Portugal (2002) e Fazolo e Portugal (2003), dão algum suporte a esta hipótese. 
estava claro qual seria o efeito da persistência inflacionária no ano. Pode-se argumentar ainda que o governo deveria impor alguns desincentivos aos capitais externos de curto prazo, tal como é feito pelo Chile, com o objetivo de reduzir possiveis choques futuros causados por um influxo destes capitais. Existe ainda uma crítica no sentido de que o governo deveria reduzir mais rapidamente a sua exposição cambial. Até maio, a política adotada era de rolar integralmente o principal dos contratos de swap cambial, transformando em dívidas denominadas em reais apenas a parte referente aos juros, o que resultou, na prática, em uma rolagem de $88 \%$ do total dos vencimentos. A partir de junho de 2003, contudo, o Banco Central eliminou qualquer regra quanto à rolagem dos swaps. Como resultado, já na renovação dos contratos ocorrida em junho, apenas 55\% do valor vincendo foi rolado em dólar. Desta forma, abriu-se espaço para uma redução paulatina da exposição cambial do Banco Central, diminuindo assim o problema do "pecado original" para a economia brasileira ${ }^{8}$.

Fugindo um pouco da política econômica, mas merecendo igual destaque pelas suas futuras implicações, está a questão das agências de regulação. O governo vem tentando reduzir o papel destas instituiçōes por meio de seus Ministérios, o que pode acarretar em redução de novos investimentos futuros por parte do setor privado e, conseqüentemente, afetar a capacidade de crescimento econômico do Brasil no médio e longo prazos. O exemplo da discussão sobre a indexação das tarifas de telefonia é emblemático. Independente dos argumentos a favor ou contra um determinado índice de preços, estes deveriam ter sido discutidos na época da realização das privatizações. A escolha por um índice geral de preços agradou na época tanto o governo, pois estes índices estavam abaixo dos demais, como as empresas, pois são índices sensiveis ao comportamento do câmbio e grande parte dos investimentos foram realizados com preços dolarizados. Dessa forma, as tentativas de modificar o índice têm efeitos positivos apenas para o governante míope que atende a uma reclamação da maioria da população no curto prazo, mas representa um perigoso sinal de alerta em relação à apreciação dos governos brasileiros a contratos, um dos pilares básicos das economias capitalistas. Além disso, como os índices de preços gerais (contento os preços no atacado) e ao consumidor tendem a apre-

${ }^{8}$ Ver Eichengreen, Hausmann, e Panizza (2002). 
sentar um comportamento semelhante no longo prazo, mudar o indexador no contrato pode inclusive levar a maiores aumentos de preços futuros para os consumidores.

Uma outra linha de críticas mais profunda à atual política econômica pode ser inferida das propostas oferecidas por alguns economistas ligados ao próprio Partido dos Trabalhadores, expressas no documento "A Agenda Interditada - Uma Alternativa de Prosperidade para o Brasil". Segundo esta visão, tem-se que mudar o eixo central da política econômica atual, ou, em outras palavras, mudar o "modelo econômico". Esta estratégia alternativa, sugere o fim do mercado de câmbio flutuante e o controle de capitais externos através de algum tipo de centralização cambial que daria ao Banco Central o poder de determinar a taxa de câmbio, a redução "significativa" (e supõe-se rápida) das taxas de juros para "favorecer a produção em detrimento da especulação", a redução do superávit primário, a fim de ampliar a demanda agregada, pela ampliação dos gas tos públicos, a montagem de "políticas de renda pactuadas para o controle da inflação", e medidas administrativas ou tarifárias de fechamento da economia. No passado, a utilização das chamadas politicas de renda acabava sempre sendo um eufemismo para a implementação de mecanismos administrativos de controles de preços como forma de combate à inflação, tais como câmaras ou acordos setoriais.

Além destas propostas não terem nenhum respaldo em alguma experiência bem-sucedida e misturarem desejos com possibilidades, o simples fato de termos influentes economistas e parlamentares do partido do governo afirmando que "a hora da virada está próxima", ou que o "Plano B" virá a qualquer momento, produz incerteza sobre o desenrolar futuro da política econômica, impedindo que se colham todos os frutos da tentativa atual de construção de credibilidade do novo governo. Para evitar maiores danos, o governo deveria minimizar a ambigüidade econômica: abraçar a política econômica atual de forma clara, isolando os dissidentes, ou assumir a implementação do plano alternativo.

\section{Conclusão}

O governo do presidente Luiz Inácio Lula da Silva foi o primeiro desde a redemocratização do Brasil, em 1985, a iniciar sem um 
"Plano Econômico". Tivemos tantos no passado: Cruzado, Bresser, Verão, Collor I, Collor Il e, finalmente, o Real.

À exceção do Plano Real, estes planos tinham em comum uma proposta "heterodoxa" de fazer política econômica, abandonando as práticas da política econômica ortodoxa ou tradicional, que são aplicadas rotineiramente na maior parte dos países bem-sucedidos do mundo. Os planos econômicos no Brasil, fora o Plano Real, nada mais eram do que um conjunto de medidas de caráter esdrúxulo com uma característica comum: ruptura generalizada de contratos e de regras econômicas básicas (congelamento geral de preços e salários) que eram digeridas pela população durante o final de semana e/ou feriado bancário. Os chamados planos econômicos heterodoxos sempre foram, na verdade, um eufemismo de ruptura. $\mathrm{O}$ Plano Real termina com este ciclo de heterodoxia econômica e rup. tura no Brasil. O Real parece ter fechado um ciclo de políticas heterodoxas com ruptura abrupta que se iniciou em 1986, quando o então presidente José Sarney optou pelo chamado Choque Heterodoxo, descartando a Proposta Larida que seria a base de elaboração do Plano Real.

É bem verdade que, durante o segundo semestre de 2002, existia uma forte incerteza quanto à possibilidade de uma nova ruptura no início do Governo Lula. Isto acabou causando uma disparada da taxa de câmbio, a aceleração da inflação e uma elevação do riscopaís, eliminando quase completamente o fluxo de recursos externos ao Brasil'.

Ao reverter as expectativas de ruptura, o Governo Lula poderá estar iniciando uma nova era, de mais maturidade e estabilidade na economia brasileira. Nestes primeiros seis meses de mandato, a construção dè um ambiente institucional estável, em que contratos e regras econômicas não estão sujeitos à ruptura, está custando relativamente caro, em termos de juros, esforço fiscal e, principalmente, baixo crescimento econômico, ao Governo Lula. Contudo, se esta

\footnotetext{
9 A chamada parada brusca (sudden stop) fez com que o fluxo total de recursos externos que havia sido de US $\$ 52,8$ bilhōes, em 2001 , caisse para apenas US $\$ 24,8$ bilhões, em 2002 . Obviamente, o aumento generalizado da aversão ao risco derivado dos escândalos contábeis em grandes corporações multinacionais colaborou para a redução dos fluxos externos para o Brasil. Contudo, quando analisamos a evolução do risco-país para o Brasil e para os demais emergentes, fica claro que a elevação do prêmio de risco brasileiro esteve muito acima da média dos países emergentes em 2002, indicando, assim, que algum fenômeno específico ao Brasil (eleições) foi determinante.
} 
estratégia for mantida por mais alguns meses, até que se consolidem as expectativas de estabilidade, os ganhos de médio e longo prazo podem ser muito grandes. O presidente Lula tem a chance de passar para a história como o exorcista da ruptura econômica no Brasil.

Os eventos econômicos dos últimos cinco meses têm mostrado que o país está atingindo também um certo grau de maturidade política. Esta maturidade é gerada pela convergência dos partidos políticos para o centro. O grau de divergência política no Brasil se reduziu significativamente. Nas duas eleições presidenciais anteriores, mas principalmente na de 1994, existiam dois projetos políticos completamente opostos. De um lado, propunha-se a abertura econômi$\mathrm{ca}$, a privatização e outras reformas liberalizantes e, de outro lado, a manutenção do modelo antigo de economia fechada, com forte intervenção e regulamentação estatal. Durante a administração Fernando Henrique Cardoso, a agenda de reformas parece ter se imposto como agenda hegemônica, adotada agora com alterações menores pela oposição de outrora.

Esta maior maturidade política, que descarta a adoção de soluções pirotécnicas de política econômica, pode gerar benefícios muito elevados para a economia brasileira no longo prazo. $O$ evento de um governo de esquerda que é "socialista no social" e "ortodoxo em termos de política econômica”, que respeita regras e contratos estabelecidos e que não tenta impor uma agenda de ruptura à sociedade, leva a um ganho de credibilidade de país como um todo e não apenas do governo que está em exercício.

Se esta nova postura de compromisso com as regras econômicas básicas, respeito a contratos e de ausência de ruptura for mantida durante todo governo Lula, o Brasil poderá superar definitivamente o susto recorrente trazido por toda eleição presidencial. Se assim for, nas próximas eleiçōes o risco-país não chegará ao patamar de 2.400 pontos e os fluxos de capitais não vão diminuir para o Brasil, como aconteceu em 2002. Ou seja, poderemos estar livres dos custos econômicos e sociais associados à incerteza trazida da ruptura brusca na política econômica.

\section{Referências Bibliográficas}

Bernanke, B., Laubach, T., Mishkin, F. S., and Posen, A. S. (1999), Inflation targeting: lessons from international experience, Princeton University Press, New Jersey, 382p. 
EichENGReEn, B., Hausmann, R. and Panizza, U. (2002), "Original Sin: the pain, the mystery and the road to redemption", working paper presented at Currency and Maturity: Redeeming Debt from Original Sin, organized by the Inter-American Development Bank (IDB) held in Washington (DC) on November 21-22 2002.

FASOLO, A. M. e Portugal, M. S. (2003), "Imperfect Rationality and Inflationary Inertia: A new estimation of the Phillips Curve for Brazil", Texto para Discussãon. 10/2003, Programa de Pós-Graduaçāo em Economia, UFRGS, 27 p.

Merurn, C. E. e Portugal M. S. (2002), "Estimating the Real Exchange Rate for Brazil: 1984-2000", Anais do XXX Encontro Brasileiro de Economia, ANPEC, Nova Friburgo (RJ), CD-Ron.

Portugal, M. S., Madalozzo, R. C. e Hillbrecht, R. O. (1999), "Inflation, Unemployment and Monetary Policy in Brazil", Anais do XXI Encontro Brasileiro de Econometria, Belém (PA), vol. II, p. 522-541.

SilvA, M. E. A. and Portugal, M. S. (2002), "Inflation Targeting in Brazil: An empirical evaluation", Revista de Economía, Banco Central del Uruguay, vol. 9, n. 2, Noviembre, p. 85-117.

TEJADA, C. A. O. e Portugal, M. S. (2002), "Credibility and Reputation: An application of the external circumstances model for the Real Plan", Revista Brasileira de Economia, vol. 56, n. 4, p. 695-727. 